\title{
Multilayered Nb-Al composite manufactured by explosive welding
}

\author{
Iuliia Maliutina ${ }^{1,2, *}$, Daria Lazurenko ${ }^{1}$, and Maxim Esikov ${ }^{1,2}$ \\ ${ }^{1}$ Department of Materials Science in Mechanical Engineering, Novosibirsk State Technical University, K. Marks 20, 630073 \\ Novosibirsk, Russia \\ ${ }^{2}$ Laboratory of Physics of High Energy Density, Lavrentyev Institute of Hydrodynamics, SB RAS, 15 Lavrentyev pr., 630090 \\ Novosibirsk, Russia
}

\begin{abstract}
In this study, the multilayered composite materials consisting of niobium and aluminum foils were produced by explosive welding. The conducted microstructural studies with the use of scanning electron microscopy (SEM) have shown that the boundaries of welded seams have predominantly a wave structure with a partial local melting of interacting materials. At the niobium/aluminum boundary, in the mixing zones, micro volumes with a non-uniform chemical composition were presented. Mechanical tests have shown that the strength properties, as well as the toughness of composite materials, are at an intermediate level relative to the initial materials.
\end{abstract}

\section{Introduction}

For many years researchers are interested in multilayer materials containing intermetallic phases, so-called metallic-intermetallic laminate (MIL) composites. To obtain materials of this type, various methods, including methods of deposition, cladding, casting, accumulation roll bonding have been used to produce multilayer compositions such as $\mathrm{Ti}-\mathrm{Al}-\mathrm{Nb}, \mathrm{Ni}-\mathrm{Al}, \mathrm{Nb}-\mathrm{Fe}$ and others [1-5]. Such materials have enhanced mechanical properties, including strength, toughness, fatigue characteristics, etc., which makes them interesting objects for research.

Among these methods, explosive welding followed by heat treatment is the most effective method of MIL composites manufacturing. It is well known that the welding process consists in accelerating the flyer plate because of the explosive located on it and its collision at very high speeds with the fixed plate. As a result of the high pressure and temperature originated at the contact point of the plates, high degrees of deformation are occurred, which ensure the formation of high-strength joints. The method makes possible to combine incompatible materials, and also to combine materials that differ in their thickness without significantly changing of their properties [6]. Thus, the bimetallic composite of dissimilar materials can be easily obtained by explosive welding [7-10]. This method also has been successfully used to obtain MIL composites consisting of alternating 10 titanium plates and 11 aluminum plates [11], as well as a seven-layer composite consisting of alternating plates of nickel and aluminum [2]. The materials involved in the formation of the above materials, namely the Ti-Al and $\mathrm{Ni}-\mathrm{Al}$, are the most interest, because of the intermetallic compounds formed during their interaction are promising candidates for the aircraft industry.

Less attention is paid to the $\mathrm{Nb}-\mathrm{Al}$ alloys, which have obvious advantages over $\mathrm{Ti}-\mathrm{Al}$ and $\mathrm{Ni}-\mathrm{Al}$ alloys. For example, intermetallic compounds of niobium and aluminum have higher melting point $\left(1680-2060{ }^{\circ} \mathrm{C}\right.$ depending on the composition), and their density is less or comparable to the density of the studied intermetallic compounds (4.54-7.28 g/ $\mathrm{cm}^{3}$ depending on the composition) [12]. Therefore, composites containing intermetallic compounds based on niobium and aluminum are of great scientific and practical interest.

The paper presents the results of structural studies and mechanical properties of multilayered compositions consisting of thin foils of niobium and aluminum obtained by explosive welding.

\section{Experimental procedure}

Multilayered compositions were obtained by explosive welding technology. The outer layers were thin plates of VT14 titanium alloys ( $\alpha+\beta$ alloy) of $0.6 \mathrm{~mm}$ thick and OT4 (near $\alpha$-alloy) of $0.3 \mathrm{~mm}$ thick (Fig. 1). Ammonite $6 \mathrm{ZhV}$ explosive of $15 \mathrm{~mm}$ thick was placed onto the VT14 titanium plate, used as a flyer plate. Titanium plates located outside the composite were used as a protection for niobium during heating, and also for testing the possibility of welding niobium with various titanium alloys. The A5 aluminum foils of $0.25 \mathrm{~mm}$ thick and Nb-1 niobium foils of $0.2 \mathrm{~mm}$ thick were alternately arranged between them. The chemical composition of the initial materials is given in Table 1. The distance between the foils and plates was about 1 $\mathrm{mm}$. Thus, a multilayered composition consisting of 7 thin plates with a total thickness of $2 \mathrm{~mm}$ was obtained.

* Corresponding author: iuliiamaliutina@gmail.com 
Table 1. The chemical composition of initial materials.

\begin{tabular}{|c|c|c|c|c|c|c|c|}
\hline \multirow{2}{*}{ Materials } & \multicolumn{7}{|c|}{ Chemical composition, wt. \% } \\
\cline { 2 - 8 } & $\mathrm{Ti}$ & $\mathrm{Al}$ & $\mathrm{Mo}$ & $\mathrm{V}$ & $\mathrm{Mn}$ & $\mathrm{Fe}$ & $\mathrm{Nb}$ \\
\hline VT14 & Bal. & 4.5 & 3.4 & 1.2 & - & - & - \\
\hline OT4 & Bal. & 4.6 & - & - & 1.1 & - & - \\
\hline A5 & - & Bal. & - & - & - & 0.25 & - \\
\hline Nb-1 & - & - & - & - & - & - & 100 \\
\hline
\end{tabular}

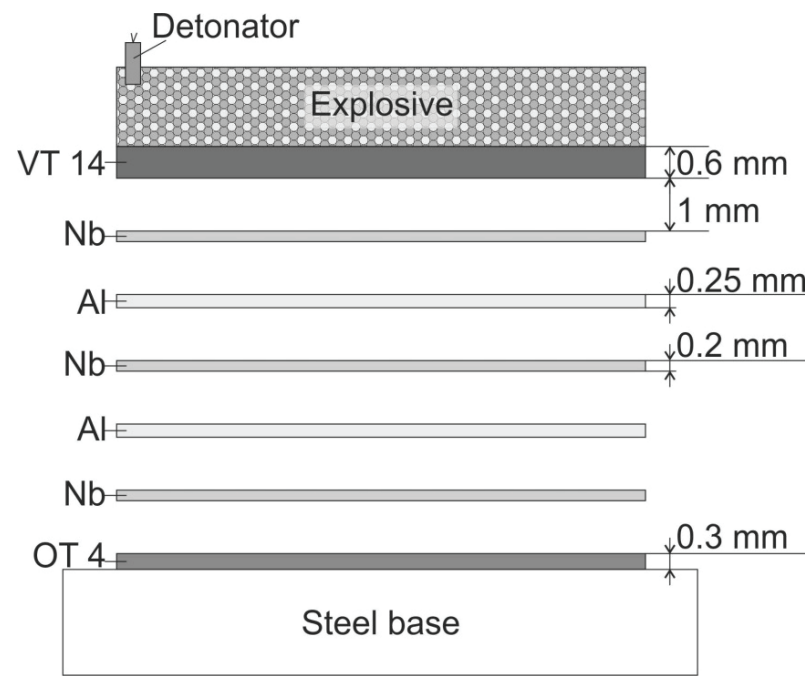

Fig. 1. The scheme of explosive welding of a seven-layer composite consisting of VT14 and OT4 titanium alloys, as well as alternating foils of niobium and aluminum.

Samples for microstructural studies were cut from the central part of the composite corresponding to the longitudinal direction of the shock wave propagation. Specimens were prepared by grinding and polishing using a fine dispersion of silicon oxide with a particle size of $0.05 \mu \mathrm{m}$. For chemical etching of titanium alloys, Kroll's was used. Microstructural studies were performed on a scanning electron microscope in a mode of secondary and back-scattered electrons. The chemical composition of reaction products formed in the zones of plates impact was analyzed by energy-dispersive microanalyzer.

The Vickers microhardness of the analyzed composites was determined on the polished transverse specimens in the direction from the VT14 plate to the OT4 plate through all the layers. The mechanical properties of the laminate composites were evaluated in the static tensile and impact tests.

\section{Results and discussions}

A detailed study of the boundaries formed during explosive welding between different materials is shown in Fig. 2 and 3. The boundaries between VT14 and OT4 titanium, as well as niobium, have a typical wave structure with local mixing areas. Near the welded seam in the titanium plates a thin layer of $5 \mu \mathrm{m}$, consisting of deformed grains, is found. This behavior indicates on a severe plastic deformation in the zone of a contact point.
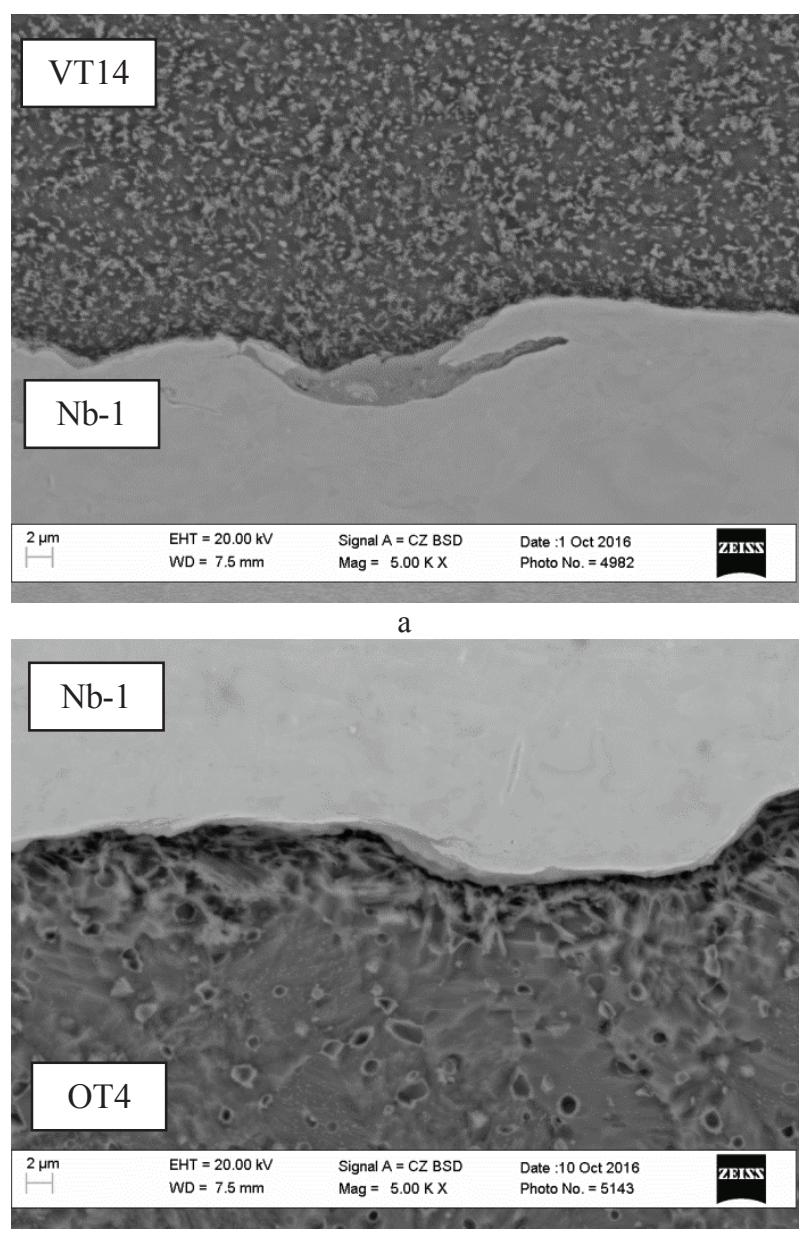

b

Fig. 2. SEM image of the $\mathrm{VT} 14 / \mathrm{Nb}$ and $\mathrm{Nb} / \mathrm{OT} 4$ boundaries joint.

At the niobium/ aluminum boundary, there are many sections corresponding to the zones of partial melting and mixing of the two materials. The SEM image shows a nonuniform distribution of aluminum and niobium in various parts of the mixing region, due to high crystallization rates of the alloys and the nonequilibrium state of the explosive welding process.

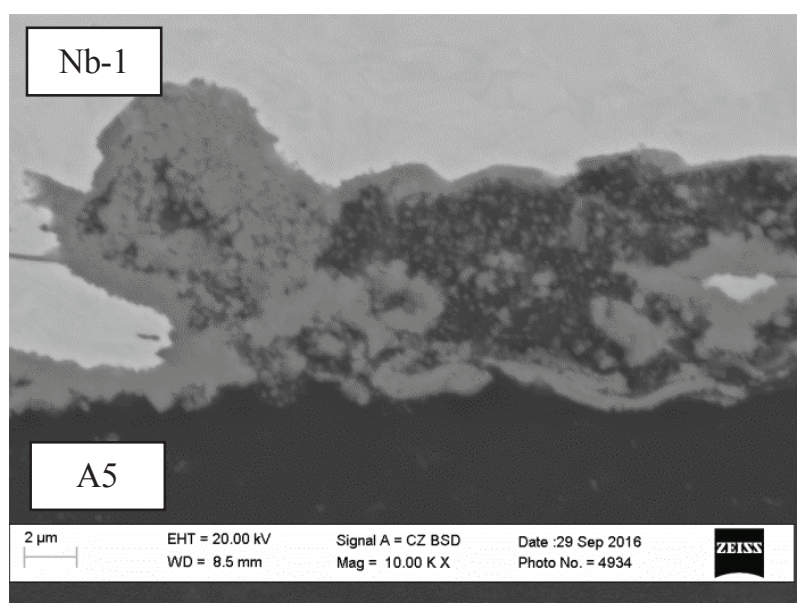




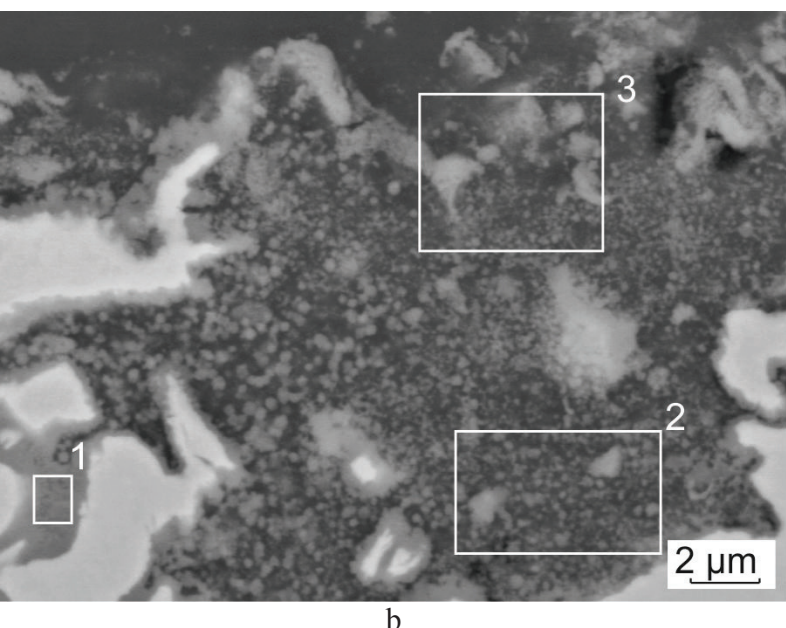

Fig. 3. SEM image of the boundary of the $\mathrm{Nb} / \mathrm{Al}$ joint (a) and the mixing zone of these materials (b).

The results of the energy dispersive analysis confirmed the different elemental composition (Table 2). The concentration of niobium varied from 3 to 26 at. $\%$.

Table 2. The content of niobium and aluminum in different parts of the mixing zone (at. \%).

\begin{tabular}{|c|c|c|}
\hline Analyzed area & Nb & Al \\
\hline 1 & 3.16 & 96.84 \\
\hline 2 & 14.9 & 85.10 \\
\hline 3 & 26.1 & 73.9 \\
\hline
\end{tabular}

The microhardness of the composites was measured in the direction from the plate of the VT14 titanium alloy to the OT4 titanium plate through all the layers. The microhardness results of the composite after explosive welding are shown in figure 4. The average microhardness of the initial materials was $260 \mathrm{HV}$ for VT14, $33 \mathrm{HV}$ for $\mathrm{Al}, 118 \mathrm{HV}$ for $\mathrm{Nb}$ and $232 \mathrm{HV}$ for OT4. In the mixing zones of niobium and aluminum, a significant increase in the microhardness was not observed, due to the nonuniform distribution of the highstrength phase and the high aluminum content in these sections.

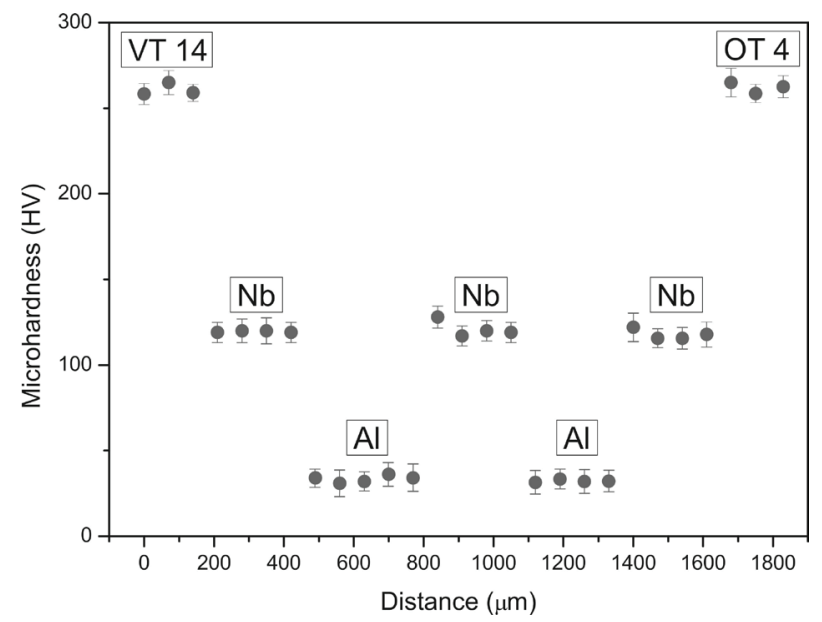

Fig. 4. Microhardness distribution in different composite layers.
The results of the mechanical properties of the composites obtained in comparison with the materials contained the composites are shown in Table 3. According to this data, the strength properties, as well as the impact strength are at an intermediate level with respect to the initial materials.

Table 3. Mechanical properties of the composite material and the initial materials.

\begin{tabular}{|c|c|c|c|c|}
\hline $\begin{array}{c}\text { Analyzed } \\
\text { materials }\end{array}$ & $\begin{array}{c}\text { Ultimate } \\
\text { tensile } \\
\text { strength, } \\
\text { MPa }\end{array}$ & $\begin{array}{c}\text { Tensile } \\
\text { yield } \\
\text { strength, } \\
\text { MPa }\end{array}$ & $\begin{array}{c}\text { Specific } \\
\text { elongation, } \\
\mathbf{\%}\end{array}$ & $\begin{array}{c}\text { Impact } \\
\text { strength, } \\
\mathbf{J} / \mathbf{s m}^{2}\end{array}$ \\
\hline Composite & 534 & 335 & - & 42,5 \\
\hline Nb-1 & 425 & 355 & 23 & 37 \\
\hline A5 & 60 & - & $20-28$ & $100-120$ \\
\hline VT14 & 1050 & 895 & $8-10$ & $45-50$ \\
\hline OT4 & $635-685$ & $550-660$ & $10-20$ & $35-40$ \\
\hline
\end{tabular}

\section{Conclusions}

Thus, it was established that explosive welding allows the formation of multilayer compositions consisting of thin niobium and aluminum foils. In accordance with microscopic analysis, it was shown that the welded seams formed during the process have a wave structure with the formation of local mixing areas. In the mixing zone of niobium and aluminum by scanning electron microscopy was detected that the composition is nonuniform so that the content of niobium varies from 3 to 26 at. $\%$. The results of mechanical tests showed that the strength properties, as well as the impact strength, are at an intermediate level with respect to the initial materials.

The obtained results indicate the possibility of chemical compounds formation at the welding interface of niobium and aluminum foils. For the subsequent growth of the formed intermetallic compounds, it is necessary to select the heat treatment mode of the explosively welded samples, and also to study the kinetics of the phase transformations that occur during heating.

The work was carried out in the frame of project No 11.7662.2017/BCh

\section{References}

1. S. Simões, A.S. Ramos, F. Viana, O. Emadinia, M.T. Vieira, M.F. Vieira, J. Mater. Eng. Perform. 25, 4394 (2016)

2. I.A. Bataev, T.S. Ogneva, A.A. Bataev, V.I. Mali, M.A. Esikov, D.V. Lazurenko, Y. Guo, A.M. Jorge Junior, Mater. Design 88,1082 (2015)

3. P. Qu, L. Zhou, V.L. Acoff, Mater. Charact. 107, 367 (2015)

4. P. Qu, L. Zhou, H. Xu, V.L. Acoff, Metall. Mater. Trans. A 45, 6217 (2014) 
5. I. A. Bataev, K. Hokamoto, H. Keno, A.A. Bataev, I.A. Balagansky, A.V. Vinogradov, Met. Mater. Int. 21, 713 (2015)

6. Iu.N. Maliutina, N.V. Stepanova, A.G. Cherkov, L.V. Chuchkova, Obrab. Met. 69, 61 (2015)

7. F. Grignon, D. Benson, K.S. Vecchio, M.A. Meyers, Int. J. Impact Eng. 30, 1333 (2004)

8. P. Manikandan, K. Hokamoto, A.A. Deribas, K. Raghukandan, R. Tomoshige, Mater. T. JIM 47, 2049 (2006)

9. Iu.N. Maliutina, V.I. Mali, I.A. Bataev, A.A. Bataev, M.A. Esikov, A.I. Smirnov, K.A. Skorokhod, The Scientific World Journal 2013, 1 (2013)

10. H. Paul, L. Lityńska-Dobrzyńska, M. Prażmowski, Metall. Mater. Trans. A 44, 3836 (2013)

11. I.A. Bataev, A.A. Bataev, V.I. Mali, D.V. Pavliukova, Materials and Design 35, 225 (2012)

12. E.P. Barth, J.K. Tien, S. Ucjo, S. Kambara, Mater. Sci. Eng. A - Struct A153, 398 (1992) 